\section{Differentiation of the Clinical Features of Psoriatic Arthritis and Fibromyalgia}

To the Editor:

I read with interest the article by Marchesoni, et al ${ }^{1}$ in which the authors state that the features distinguishing fibromyalgia syndrome (FM) from psoriatic arthritis (PsA) were the number of FM-associated somatic symptoms and tender point count, not the Maastricht Ankylosing Spondylitis Enthesitis Score (MASES) ${ }^{2}$. But the alternative diagnostic criteria for FM, the American College of Rheumatology (ACR) $2010 \mathrm{criteria}^{3}$, are based on patient self-assessment without any tender point count. On the other hand, there is an argument for the somatic symptoms of 41 items that are considered specific for $\mathrm{FM}^{4}$, but Marchesoni, et al considered them as confusing the diagnostic criteria of FM of 2010 with those of $1990^{5}$

Surely, the presence of FM among rheumatic diseases can confuse accurate evaluation of spondyloarthritis $(\mathrm{SpA})^{6}$, which is the main cause of diagnostic confusion in the 1990 ACR diagnostic criteria ${ }^{7}$. FM is often misdiagnosed, particularly with SpA. According to our survey using the 1990 ACR diagnostic criteria, FM is complicated with SpA in $25.3 \%$ of cases and SpA is complicated with FM in $38.9 \%$ of cases, respectively (Table 1).

The main reason for confusion in diagnoses of FM and SpA is due to overlap of the extensive enthesitis in SpA with the tender points of FM in the ACR 1990 diagnostic criteria ${ }^{8}$.

Is there any relationship between the tender points seen in FM and enthesitis? Does FM have an inflammatory character such as rheumatoid arthritis (RA) and SpA?

According to Marchesoni, et al, unlike the MASES result, the frequency of the inflammatory changes seen in power Doppler ultrasound (PDUS) of the entheses in PsA was greater than that for FM.

Table 1. FM was complicated with SpA in $25.3 \%$ of cases and SpA was complicated with FM in $38.9 \%$ of cases.

\begin{tabular}{ll}
\hline $\mathrm{SpA} / \mathrm{FM}$ & 33 cases/130 cases $(25.3 \%)$ \\
$\mathrm{FM} / \mathrm{SpA}$ & 23 cases $/ 59$ cases $(38.9 \%)$
\end{tabular}

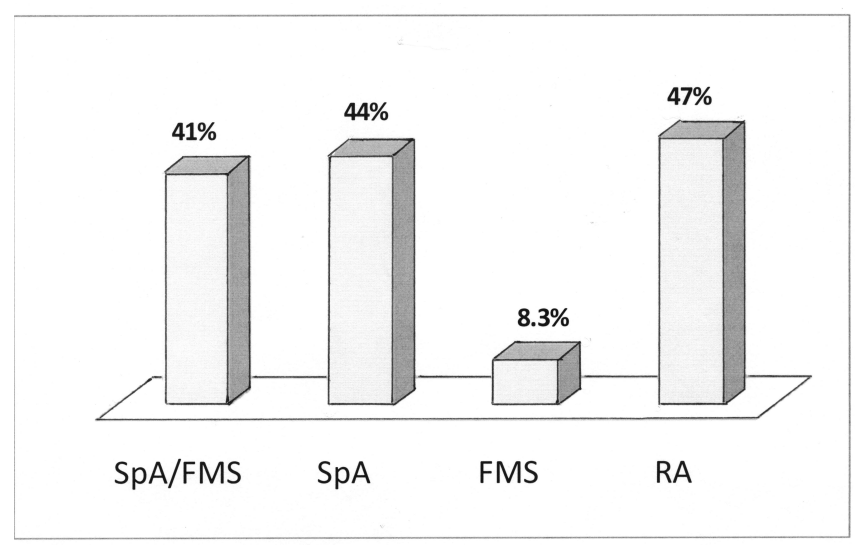

Figure 1. The frequency of entheseal changes (erosive changes) was confirmed in $8.3 \%$ of cases of primary FM, and increased in cases of FM complicated with SpA, SpA alone, and all RA cases.
Using PDUS, we also examined enthesitis due to primary FM (24 cases; that is, FM based on mental aspects or complex regional pain syndrome), SpA (70 cases), SpA complicated with FM (FM/SpA; 22 cases), and RA (17 cases) $)^{9}$. As shown in Figure 1, the frequency of entheseal changes (erosive changes) was confirmed in $8.3 \%$ of cases of primary FM, and increased to more than $40 \%$ in FM complicated with SpA, SpA alone, and all RA cases; therefore, primary FM is different from RA and SpA, which are inflammatory diseases $(\mathrm{p}<0.001)$.

Although Marchesoni, et al showed that inflammatory changes were present in $70 \%$ of patients with PsA but also in $21.3 \%$ of patients with FM on PDUS, and therefore PDUS is not specific for differentiation of PsA and FM, PDUS will be helpful to rule out the presence or existence of enthesitis, or to differentiate noninflammatory primary FM and inflammatory SpA.

The tender point determination of the 1990 ACR diagnostic criteria becomes extinct in the ACR 2010 diagnostic criteria set, which is based on patient self-assessment of somatic symptoms, which are not constant. Therefore, for approaching the essence of enthesitis, it is important at present to introduce application of PDUS for differentiation of SpA and FM.

TAKAHIKO KONNO, MD, PhD, Division of Rheumatology, Tokeidai Memorial Clinic, North-1, East-1, Sapporo, Japan. Address correspondence to Dr. Konno; E-mail: taiki@snow.plala.or.jp

\section{REFERENCES}

1. Marchesoni A, Atzeni F, Spadaro A, Lubrano E, Provenzano G, Cauli A, et al. Identification of the clinical features distinguishing psoriatic arthritis and fibromyalgia. J Rheumatol 2012;39:849-55.

2. Heuft-Dorenbosch L, Spoorenberg A, van Tubergen A, Landewe R, van der Tempel H, Mielants H, et al. Assessment of enthesitis in ankylosing spondylitis. Ann Rheum Dis 2003;62:127-32.

3. Wolfe F, Clauw DJ, Fitzcharles MA, Goldenberg DL, Katz RS, Mease P, et al. The American College of Rheumatology preliminary diagnostic criteria for fibromyalgia and measurement of symptom severity. Arthritis Care Res 2010;62:600-10.

4. Smythe HA. Unhelpful criteria sets for "diagnosis" and "assessment of severity" of fibromyalgia [editorial]. J Rheumatol 2011;38:975-8.

5. Wolfe F, Smythe HA, Yunus MB, Bennett RM, Bombardier C, Goldenberg DL, et al. The American College of Rheumatology 1990 criteria for the classification of fibromyalgia. Report of the Multicenter Criteria Committee. Arthritis Rheum 1990;33:160-72.

6. Fitzcharles MA, Boulos P. Inaccuracy in the diagnosis of fibromyalgia syndrome: Analysis of referrals. Rheumatology 2003;42:263-7.

7. Almodovar R, Carmona L, Zarco P, Collantes E, Gonzalez C, Mulero J, et al. Fibromyalgia in patients with ankylosing spondylitis: Prevalence and utility of the measures of activity, function and radiologic damage. Clin Exp Rheumatol 2010; 28:S33-9.

8. Mander M, Simpson JM, Mclellan A, Walker D, Goodacre JA, Dick WC. Studies with an enthesis index as a method of clinical assessment in ankylosing spondylitis. Ann Rheum Dis 1987;46:197-202.

9. Falsetti P, Frediani B, Acciai C, Filippou G, Galeazzi M, Marcolongo R. The role of ultrasonography of peripheral entheses in the diagnosis and assessment of spondyloarthropathies. Curr Rheumatol Rev 2005;1:243-254.

J Rheumatol 2012;39:11; doi:10.3899/jrheum.120798 